\title{
Gender Differences in Real-Home Sleep of Young and Older Couples
}

\author{
Maryam Butt, MSc $^{1}$ \\ Stuart F. Quan, $M D^{3,4,5}$ \\ Alex (Sandy) Pentland, $P h D^{2}$ \\ Inas Khayal, $P h D^{1,2}$ \\ ${ }^{1}$ Masdar Institute of Science and Technology, Abu Dhabi, UAE \\ ${ }^{2}$ Massachusetts Institute of Technology, Cambridge, MA, USA \\ ${ }^{3}$ Division of Sleep Medicine, Harvard Medical School, Boston, MA, USA \\ ${ }^{4}$ Arizona Respiratory Center, University of Arizona College of Medicine, Tucson, AZ, \\ USA \\ ${ }^{5}$ Division of Sleep and Circadian Disorders, Brigham and Women's Hospital, Boston, \\ MA, USA
}

\begin{abstract}
Study Objectives: To understand gender differences in sleep quality, architecture and duration of young healthy couples in comparison to older couples in their natural sleep environment.

Design: Sleep was monitored in a naturalistic setting using a headband sleep monitoring device over a period of two weeks for young couples and home polysomnography for the older couples.

Participants: Ten heterosexual young couples (male mean age: $28.21 .0[S D]$ years /female mean age: 26.80 .9 years) and 14 older couples (male mean age: $59.3+9.6$ years/female mean age: $58.8+9.1$ years).

Measurements and results: In the young couples, total sleep time (395+66 vs. $367+54$

min., $p<0.05)$, sleep efficiency $(97.0+3.0$ vs. $91.1+7.9, p<0.001)$, and $\%$ REM $(31.1+4.8$ vs. $23.6+5.5, p<0.001)$ in males was higher than in females. In contrast, $\%$ light sleep $(51.7+7.1$ vs. $59.7+6.7, p<0.001)$ and number of arousals $(2.9+1.9$ vs. $5.3+1.9$, $p<0.001$ ) were lower. These differences persisted after controlling for evening mood and various evening pre-sleep activities. In the older couples, there were no differences between genders. In addition, children in the household adversely impacted sleep. Conclusions: In couples recorded in the home, young males slept longer and had better sleep quality than young females. This difference appears to dissipate with age. Inhome assessment of couples can aid in understanding of gender differences in sleep and how they are affected by age and social environment.
\end{abstract}

\section{Introduction}

Sleep has a considerable public health impact and is needed to maintain optimal health and well-being. Impaired sleep has been shown to have adverse health effects from psychiatric illnesses such as depression (1) to physical health risks such as obesity and diabetes (2-4). Poor sleep has also been shown to lead to behavioral consequences such as sleepiness, impaired cognitive function, low job performance and motor vehicle 
accidents resulting in both health and financial losses (5). However, the prevalence of sleep disturbances varies according to both age and gender (6). In addition, objective assessments of sleep find that sleep architecture changes as a function of both these factors (7). This was confirmed in a study by Redline et al in which interactions between age and gender were an important factor in explaining variations in sleep architecture (8).

Studies investigating gender differences in sleep have mostly relied on laboratory polysomnography (PSG), wrist actigraphy and subjective survey instruments (9-11). These studies have not been able to capture sleep quality, architecture and duration from the subject's natural sleep environment, which may be surrounded and affected by their bed partner, children or their routine sleep schedule. Furthermore, in many of these studies, the age spectrum of the participants was limited $(9,12)$. With the recent availability of home sleep monitoring devices, it is now possible to objectively measure detailed sleep parameters in subjects' real-home environment. This methodology attempts to minimize any disruptions to an individual's naturalistic sleep setting. The purpose of this study was to utilize a portable sleep monitoring device to measure detailed sleep parameters of young healthy couples in their real-home environment to study gender differences. In addition, we compared these results to home sleep recordings obtained from older adults to assess whether there were changes with age. We hypothesize that sleep parameters measured in a naturalistic setting will be affected by gender given the different social roles of young married men and women. In addition, we posited that these changes would evolve with age.

\section{Methods}

\section{Study Populations}

Graduate Student Cohort. This cohort consisted of 10 young healthy married heterosexual couples. The participants were residents of a vibrant married graduatestudent community about half of whom had children. The mean age of male subjects was 28.2 years $(S D \pm 1.0)$ and the mean age for females was 26.8 years $(S D \pm 0.9)$. Fourteen of the 20 subjects were M.S. and Ph.D. students (10 males and 4 females). The remaining subjects were spouses that were not students. Four couples had children while the remaining did not. Flyers and e-mail messages were used to recruit participants. We recruited couples in which both members were willing to participate. The inclusion criteria also required the couples to share the sleep environment. Participants did not receive any financial compensation for their participation in this experiment. Data were collected over a period of two weeks in March and April 2011 in a naturalistic setting while participants underwent their normal routine activities.

Older Couples Cohort. This cohort was comprised of 14 married couples randomly selected from participants in the Sleep Heart Health Study (SHHS) none of whom were found to have obstructive sleep apnea (Apnea Hypopnea Index $<5$ events/hour). The mean age of male participants was 59.3 years $(S D \pm 9.6)$ and the mean age for females was 58.8 years $(S D \pm 9.1)$. Overall recruitment in the SHHS has been previously 
reported $(13,14)$. Briefly SHHS participants were recruited from several ongoing longitudinal cohort studies of cardiovascular or pulmonary disease. In addition to information obtained by their parent studies, they were asked to undergo an ambulatory polysomnogram and collection of data relevant to sleep. We used data from the first examination of SHHS (1995-1997) for this analysis.

\section{Polysomnogram Data Collection}

For the Graduate Student Cohort, detailed sleep parameters were recorded using an automated wireless system (ZEO Inc., Newton, MA) which includes an elastic headband and a bed-side unit. It has been validated and found to be reliable and accurate for monitoring sleep in healthy adults $(15,16)$. Sensors embedded on the headband detect single-channel frontal EEG (electroencephalographic) signals. The headband wirelessly transmits these signals to the bedside unit where the signals are then classified into the various sleep stages by an automated algorithm. The raw EEG data are not stored by the device. The bedside unit stores the sleep stage architecture (hypnogram) data onto the SD card located in the unit. The processed data can then be exported for analysis. The headband, unlike PSG electrodes, can be worn around the forehead without the use of any adhesive that makes it very simple and comfortable to use.

Each husband and wife couple were provided with the sleep monitoring device and were asked to use it for a minimum of 14 nights in their homes. The measured sleep parameters included: total sleep time (TST), rapid eye movement (Stage R, REM), time in non-slow wave NREM (Stages N1+N2, "Light Sleep"), and slow wave NREM (Stage N3, "Deep Sleep") sleep, latency to first onset of sleep and number of awakenings. Sleep efficiency was calculated as the TST/(TST+Total Wake Time).

For the SHHS participants, as previously described, PSG was performed in an unattended setting at home (Compumedics PS-2 system; Compumedics Pty. Ltd, Abbotsville, Australia). The following channels were recorded: electroencephalogram (C3/A1 and C4/A2), right and left electrooculograms, submental electromyogram, nasal/oral airflow recorded by thermocouple (Protech, Woodenville, WA), rib cage and abdominal movement recorded by inductive plethysmography, oxyhemoglobin saturation ( $\mathrm{SpO} 2$ ) by pulse oximetry (Nonin, Minneapolis, $\mathrm{MN}$ ), and electrocardiogram. Leg movements were not recorded. Standardized techniques for sensor attachment and quality assurance were used and have been previously published (17).

\section{Survey}

Participants were asked to complete a questionnaire each morning about activities performed in the two hours prior to sleeping along with their happiness and stress levels before sleeping. Mood was measured on a scale of 1-7 (i.e., Happiness, 1: very unhappy 4: neither unhappy nor happy 7: very happy). Activities prior to sleeping included mental work (e.g., office work or studying for an exam), physical work (e.g., washing dishes, putting children to bed), heated arguments, etc. Food and beverage 
intake included caffeine and alcohol consumption. Activities prior to sleeping, and food and beverage consumption were measured on a scale of 1-5 (e.g., Physical activities 1: none at all 5: all the time, and caffeine intake 1: none at all, 5: a large amount). Subjects were also asked to report any cause of their sleep disturbances. Three options were provided which included disturbances by their spouse, children and other reasons. These were measured on a scale of 1-3, where 1: none at all, 3: a lot.

\section{Data Analysis}

For the Graduate Student Cohort, the few nights when subjects reported the headband falling off were eliminated from all analyses. Some participants provided recordings of less than 14 nights while others used the device for longer durations (up to 19 nights) giving a total of 281 recording nights for the sleep analysis. The mean number of nights per participant was 14 nights (SD: \pm 0.82 ). In this cohort, the sleep of males was compared to females using mixed-effects linear regression models. The outcome variables were the parameters of sleep architecture and gender represented the sole fixed independent variable. Individual recordings for each participant were fitted as random effects to account for serial intraparticipant correlations. In preliminary analyses, the impact of repetitive recording nights was tested, and was not found to have any effect on the findings.

Multiple regression analysis also was performed in the Graduate Student Cohort to understand how pre-sleep mood and activities affected sleep parameters. The independent variables included the pre-sleep activities and mood variables that showed significant gender differences on univariate testing by analysis of variance. Activities and mood were coded as dummy variables ( 0 : no activity and 1 : when the activity was performed). Gender (0: Female, 1: Male) and children (0: without children, 1: with children) were also added as covariates. There were a total of 206 nights with both survey and sleep information. The analyses were performed for the following sleep parameters: Total Sleep Time, Wake Time, Sleep Latency, Sleep Efficiency, \% Light Sleep \%, Deep Sleep \% and REM \% as the dependent variables. The standardized coefficient $\beta$ is reported as a measure of strength of the relationship. We considered $p$ values less than or equal to 0.01 as indicating statistical significance.

For the SHHS cohort, there was only a single night of recording. Comparisons between males and females were performed using a one way analysis of variance with sleep architecture parameters as the dependent variables and gender as the independent variable.

In order to compare the two cohorts, the aggregated mean for each sleep architecture parameter was calculated for the Graduate Student Cohort. In the SHHS cohort, N1 and N2 sleep were combined as "Light Sleep" and N3 sleep was considered equivalent to "Deep Sleep" to provide comparability to the Graduate Student Cohort. Within each gender, differences in sleep parameters were contrasted using a one way analysis of variance. 
Data are presented as mean \pm SD or as regression coefficients $(\beta)$. In the case of the Graduate Student Cohort, the data represent the mean of all recording nights.

\section{Results}

In Table 1 is shown the sleep architecture for both cohorts stratified by gender.

Table 1. Sleep Architecture in Young and Older Couples

\begin{tabular}{|c|c|c|c|c|c|}
\hline Sleep Parame & ters & Young Co & ples & Older Col & ples \\
\hline & & & Female & & Female \\
\hline $\begin{array}{l}\text { Total Sleep Th } \\
\text { Seev Eficien }\end{array}$ & e (min) & $\begin{array}{l}395+66^{a} \\
970+30^{b}\end{array}$ & $\begin{array}{l}367+54 \\
911+79\end{array}$ & $\begin{array}{l}371 \pm 62 \\
830+97^{c}\end{array}$ & $\begin{array}{l}400+39 \\
87+9+56\end{array}$ \\
\hline Sleep Latency & (ini) & $17 \pm 12$ & $19 \pm 6$ & $17.9 \pm 125$ & $227 \pm 18.6$ \\
\hline Light Sleep (\%) & & $51.7 \pm 7.1^{6}$ & $597 \pm 6.7$ & $63.7 \pm 96^{e}$ & $58.5 \pm 10.9$ \\
\hline Deep Sleep ( $\%$ & & $17.2 \pm 47$ & $16.7 \pm 5.3$ & $11.7 \pm 7.2^{6}$ & $17.7 \pm 11.6$ \\
\hline REM (\%) & & $31.1 \pm 48^{6}$ & $236 \pm 5.5$ & $24.6 \pm 7.0^{\circ}$ & $23.8 \pm 6.9$ \\
\hline Arousals (\#) & & $29+1.9^{6}$ & $5.3 \pm 1.9$ & $11.7 \pm 1.6^{c}$ & $125 \pm 1.6^{t}$ \\
\hline${ }^{a} p<0.05$ & $\mathrm{Mal}$ & s. Fema & & & \\
\hline${ }^{b} p<0.001$ & Male & s. Fema & & & \\
\hline${ }^{c} p<0.001$ & Grad & ate Stud & ent Mal & VS & Males \\
\hline${ }^{d} p<0.05$ & Grad & ate Stu & ent Male & vs. O & Males \\
\hline${ }^{e} p<.01$ & Grad & ate St & nt $\mathrm{Ma}$ & vs. O & r Males \\
\hline$f p<.05$ & Gra & : & Fom & es ves & Ee \\
\hline
\end{tabular}

In the Graduate Student Cohort, total sleep time, sleep efficiency and \%REM sleep were higher in males than females (Table 1 and Figure 1).
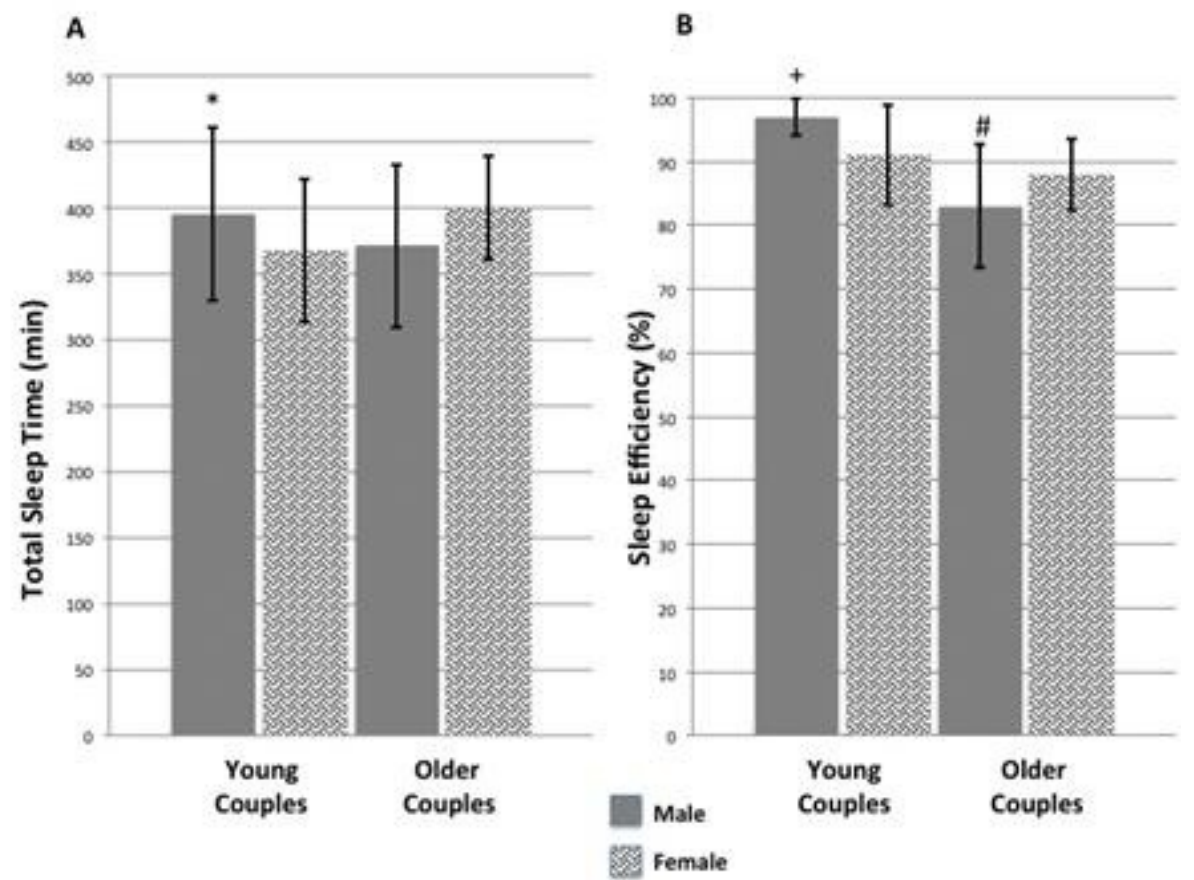

Figure 1. Panel A: Total sleep time in minutes. Panel B: Sleep efficiency (5). ${ }^{*} p<0.05$ graduate student males compared to females. ${ }^{+} p<0.001$ graduate student males compared to females. $\# p<0.001$ graduate student males compared to older males. 
Light sleep and arousals were lower. In sensitivity analyses, we restricted the dataset only to nights where both couples wore the recording device and also only to nights where no caffeine was consumed. Our findings were substantially the same in either case. In contrast, there were no significant differences between males and females in the SHHS cohort. When the sleep of the Graduate Student Cohort was compared to the SHHS cohort, differences were generally confined to males. Males in the SHHS cohort had lower sleep efficiency, \% REM and \% Deep Sleep, and higher amounts of arousals and \% Light Sleep. The only difference observed in female comparisons was the higher number of arousals in the SHHS cohort.

Table 2 illustrates the impact of children in the households of the Graduate Student Cohort. In those without children sleep efficiency was slightly better and the number of arousals was marginally less.

Table 2. Impact of Children on Sleep Architecture in Graduate Student Couple

\begin{tabular}{|c|c|c|}
\hline Sleep Parameters & $\begin{array}{l}\text { Without } \\
\text { Chtdon }\end{array}$ & Whath Childen \\
\hline Total Skep Time (min) & $392+90$ & $390+93$ \\
\hline Sleep Eficiency (\%) & $95.9+50^{2}$ & $928+91$ \\
\hline Sleep Latency (min) & $16 \pm 14$ & $22 \pm 24$ \\
\hline Light Sleep $(\%)$ & $560+95$ & $54.8+100$ \\
\hline Deep Sleep (\%) & $16.4+7.4$ & $17.0 \pm 5.0$ \\
\hline REM (\%) & $276+66$ & $28.1+9.6$ \\
\hline Arousals (\#) & $37+3.1^{\circ}$ & $44+3.2$ \\
\hline
\end{tabular}

${ }^{a} p<0.01 \quad$ Without children vs. with children

${ }^{b} \mathrm{p}=0.088 \quad$ Without children vs. with children

Males and females were also found to differ in their mood and activities prior sleeping. Females reported being happier prior sleeping than males $(5.13 \pm 1.17$ vs. $4.55 \pm 1.15$, $p<0.001)$. There were trends for males to be more involved with mental work $(2.65 \pm 1.62$ vs. $2.03 \pm 1.47, p=0.02)$ and to consume more caffeine $(1.36 \pm 0.76$ vs. $1.17 \pm 0.61$, $p<0.03)$ prior sleeping. In contrast, females did more physical work $(1.23 \pm \overline{0} .55$ vs. $1.92 \pm 1.15, p<0.001)$ and tended to eat more food $(1.83 \pm 1.01$ vs. $1.57 \pm 0.80, p=0.023)$.

The impact of evening activities on nighttime sleep is presented in Table 3. As shown by the model's negative $\beta$ coefficient, total sleep time was adversely impacted by female gender and mental work. In contrast, wake time was increased by gender, food intake and possibly physical work, but decreased by mood (happiness). The remaining sleep variables except for \% Deep Sleep also were impacted by gender. In addition, as shown in Table 3, sleep latency, sleep efficiency, \% Light Sleep, \% Deep Sleep and \% REM were variously affected by evening activities. 
Table 3. Impact of Evening Pre-sleep Activities, Mood and Gender on Sleep in Graduate Students $(n=206)$

\begin{tabular}{|c|c|c|c|c|c|c|c|c|}
\hline \multirow[t]{2}{*}{$\begin{array}{l}\text { Independent } \\
\text { Variables }\end{array}$} & & \multicolumn{7}{|c|}{ Skeep Variables ${ }^{a}$} \\
\hline & & $\begin{array}{l}\text { Total } \\
\text { Skeep } \\
\text { Trme }\end{array}$ & $\begin{array}{l}\text { Wake } \\
\text { Tme }\end{array}$ & $\begin{array}{l}\text { Sleep } \\
\text { Latency }\end{array}$ & $\begin{array}{l}\text { Sleep } \\
\text { Eficiency }\end{array}$ & $\begin{array}{l}\text { \%o } \\
\text { Light } \\
\text { Sleep }\end{array}$ & $\begin{array}{l}\text { \% } \\
\text { Deep } \\
\text { Sleep }\end{array}$ & $\%$ REM \\
\hline Gender & $\begin{array}{l}\boldsymbol{\beta} \\
\mathbf{p}\end{array}$ & $\begin{array}{l}-0.174 \\
0.015\end{array}$ & $\begin{array}{l}0.355 \\
<.001\end{array}$ & $\begin{array}{l}0.227 \\
0.002 \\
\end{array}$ & $\begin{array}{l}-0.334 \\
<0.001\end{array}$ & $\begin{array}{l}0.411 \\
<0.001\end{array}$ & $\begin{array}{l}-0.129 \\
\text { NS }\end{array}$ & $\begin{array}{l}-0.385 \\
0.001\end{array}$ \\
\hline Happiness & \begin{tabular}{|l}
$\boldsymbol{\beta}$ \\
$\mathbf{p}$
\end{tabular} & $\begin{array}{l}0.094 \\
\text { NS }\end{array}$ & $\begin{array}{l}-0.234 \\
<0.001\end{array}$ & $\begin{array}{l}-0.161 \\
0.017\end{array}$ & $\begin{array}{l}0.236 \\
<0.001\end{array}$ & $\begin{array}{l}-0.023 \\
\text { NS }\end{array}$ & $\begin{array}{l}0.109 \\
\text { NS }\end{array}$ & $\begin{array}{l}-0.58 \\
\text { NS }\end{array}$ \\
\hline $\begin{array}{l}\text { Physical } \\
\text { Work }\end{array}$ & \begin{tabular}{|l} 
p \\
$\mathbf{p}$
\end{tabular} & $\begin{array}{l}0.001 \\
\text { NS }\end{array}$ & $\begin{array}{l}0.155 \\
0.013\end{array}$ & $\begin{array}{l}-0.026 \\
\text { NS }\end{array}$ & $\begin{array}{l}-0.151 \\
0.016\end{array}$ & $\begin{array}{l}0 \\
\text { NS }\end{array}$ & $\begin{array}{l}0.227 \\
0.001\end{array}$ & $\begin{array}{l}-0.181 \\
0.004\end{array}$ \\
\hline Mertal Work & \begin{tabular}{|l|}
$\mathbf{\beta}$ \\
$\mathbf{P}$ \\
\end{tabular} & $\begin{array}{l}-0.252 \\
<0.001\end{array}$ & $\begin{array}{l}-0.065 \\
\text { NS }\end{array}$ & $\begin{array}{l}-0.088 \\
\text { NS }\end{array}$ & $\begin{array}{l}0.04 \\
\text { NS }\end{array}$ & $\begin{array}{l}0.168 \\
0.006 \\
\end{array}$ & $\begin{array}{l}0.228 \\
0.001 \\
\end{array}$ & $\begin{array}{l}0.019 \\
\text { NS }\end{array}$ \\
\hline Food & \begin{tabular}{|l|}
$\mathbf{\beta}$ \\
$\mathbf{p}$ \\
\end{tabular} & $\begin{array}{l}-0.099 \\
\text { NS }\end{array}$ & $\begin{array}{l}0.158 \\
0.009 \\
\end{array}$ & $\begin{array}{l}-0.709 \\
\text { NS }\end{array}$ & $\begin{array}{l}-0.183 \\
0.003\end{array}$ & $\begin{array}{l}0.029 \\
\text { NS }\end{array}$ & $\begin{array}{l}-0.57 \\
\text { NS }\end{array}$ & $\begin{array}{l}0.011 \\
\text { NS }\end{array}$ \\
\hline Caffeine & $\begin{array}{l}\boldsymbol{\beta} \\
\mathbf{p}\end{array}$ & $\begin{array}{l}-0.007 \\
\text { NS }\end{array}$ & $\begin{array}{l}-0.019 \\
\text { NS }\end{array}$ & $\begin{array}{l}\text { 0.036 } \\
\text { NS }\end{array}$ & $\begin{array}{l}0.025 \\
\text { NS }\end{array}$ & $\begin{array}{l}0.047 \\
\text { NS }\end{array}$ & $\begin{array}{l}-.022 \\
\text { NS }\end{array}$ & $\begin{array}{l}-0.038 \\
\text { NS }\end{array}$ \\
\hline R Squared & & 0.072 & 0.245 & 0.069 & 0.232 & 0.224 & 0.114 & 0.246 \\
\hline
\end{tabular}

${ }^{a}$ Variables analyzed in each model with their respective $\beta$ and $p$ values are shown vertically underneath each dependent sleep variable.

${ }^{\mathrm{b}}$ The overall $\mathrm{R}^{2}$ for each model

\section{Discussion}

In this study of couples sleeping together, we found that the naturalistic sleep of young males was better than females, but that these differences were not apparent in the sleep of older adults. Comparison of these groups indicated that the changes were a result of a decline in sleep quality in males. Including assessments of mood and presleep activities in analyses did not substantially affect observed differences in sleep between genders in the younger couples. We also noted that children in the household had a negative effect on sleep quality.

We observed that total sleep time, sleep efficiency and \%REM sleep were higher in young males than young females. This finding is consistent with most previous studies observing that symptoms of sleep disturbances are less common in males $(6,18-22)$. In contrast, previous polysomnographic recordings generally show better sleep quality among females $(7,8,10,23-27)$, but many of these studies were conducted using only older populations $(8,23,25,26)$. Nevertheless, in the few polysomnographic studies performed that have included younger individuals, there have been discordant results 
with no differences observed between genders (7) or females exhibiting better sleep $(24,27)$. However, only one of these was performed in a home environment and also analyzed the impact of bedpartners (27). In that study, sleep latency was longer in those sleeping with a bedpartner, but may have been confounded by age because older subjects were more likely to sleep by themselves (27). Although females in today's society are more likely to have careers outside the home, they nonetheless still may shoulder a greater burden of the household chores as we found in our study. This may translate into a shorter duration of sleep and poorer sleep quality, and may represent the difference in social roles of married women relative to their partners. However, this is likely not the entire explanation because differences in total sleep time and sleep architecture persisted even after controlling for pre-sleep evening activities.

One explanation for our novel finding of better sleep in young males living with a bedpartner is our assessment of sleep in a naturalistic environment. Most previous studies that have recorded sleep have utilized laboratory PSG $(7,8,10,23-27)$. Although it is considered the "gold standard" for objectively assessing sleep, the unfamiliar environment of a laboratory can disturb and change an individual's usual sleep quality and quantity from that under habitual conditions (28-30). Laboratory PSG does not allow subjects to sleep in their naturalistic environment and follow their usual bedtime rituals. Hence, these studies are unable to capture the contribution of their routine behaviors on their sleep and may not be reflective of the subject's home sleep. In-home studies have utilized methods such as actigraphy. However, it only indirectly detects sleep/wake patterns and is prone to inaccuracies by misinterpreting quiet wakefulness as sleep (31, 32). Furthermore, actigraphy cannot evaluate the different stages of sleep precluding studies to understand gender differences in these. Although survey collected information can assess sleep in a real-life environment, data can be incomplete, inaccurate and subject to recall bias (33). Our study overcomes the aforementioned limitations of PSG, actigraphy and surveys by capturing detailed sleep parameters in a real-home environment using a validated portable relatively unobtrusive sleep monitoring device and may be a model for future naturalistic sleep research.

The difference in sleep between genders we observed in our younger couples did not persist in the older couples. This appears to be related to disproportionate deterioration in sleep quantity and quality in males. Previous cross-sectional analyses of sleep in older persons have also found that sleep in males appears to be worse than in females $(7,8,23,27)$. These previous observations in combination with our findings indicate as suggested by others (23), that over the lifespan, the sleep of males changes at a more rapid rate than in females.

Another interesting, but perhaps not surprising result was that couples without children had more and less interrupted sleep than those without children. Although parenthood is an important life event, very few studies have looked at sleep quality and architecture differences in people with and without children. An epidemiological study of sleep duration in United States found that parents with young children were more likely to get less sleep than those without children (34). Furthermore, the presence of children affects parents' bedtimes and risetimes (35). However, these studies are based on self- 
reported data. Our results suggest that these differences should be further explored to understand how demographic and social factors impact our sleep quality and architecture.

One of the limitations of this study is its small sample size. Further larger studies should be performed to validate these results. Second, sleep staging by the sleep monitoring device is less accurate for distinguishing between wake and sleep in comparison to scoring by a sleep expert (16). However, scoring of other stages is more accurate. Third, although the heterogeneity of subjects in terms of profession and demographic factors, such as children allows comparison within the different groups, it prevents us from making strong conclusion of any one group due to limitations of the sample size. Further studies with similar sample size should try to maximize the homogeneity of the subjects. Finally, our comparison analysis should be interpreted cautiously. The cohorts were recruited separately and sleep was recorded using different instrumentation and under different protocols.

In conclusion, this study utilized a novel in-home sleep monitoring device to capture the sleep quality, architecture and duration of young couples from their natural sleep environment. The results suggest that young males have better sleep quality than females. Additionally, comparison of young couples sleep to older couples suggests that differences between genders evolve over time. Future studies including larger populations should perform in-home assessment of sleep parameters of couples of all ages to understand the effect of gender on these in a naturalistic setting.

\section{Acknowledgements}

This work has been presented at the 27th Annual Meeting of the Associated Professional Sleep Societies (APSS) in Baltimore, MD, June 2013. It was partially sponsored by Masdar Institute Fellowship, MIT/Masdar Collaborative Research Grant and MIT Media Lab Consortium as well as by HL53938 from the National Heart, Lung and Blood Institute. Dr. Quan is supported by AG009975 from the National Institute of Aging.

\section{References}

1. Al-Abri MA. Sleep Deprivation and Depression: A bi-directional association. Sultan Qaboos Univ Med J. 2015;15(1):e4-6. [PubMed]

2. Knutson KL, Van Cauter E. Associations between sleep loss and increased risk of obesity and diabetes. Ann N Y Acad Sci. 2008;1129:287-304. [CrossRefl [PubMed]

3. Van Cauter E, Knutson KL. Sleep and the epidemic of obesity in children and adults. Eur J Endocrinol. 2008;159 Suppl 1S59-66. [CrossRef] [PubMed]

4. Cappuccio FP, D'Elia L, Strazzullo P, Miller MA. Quantity and quality of sleep and incidence of type 2 diabetes: a systematic review and meta-analysis. Diabetes Care. 2010;33(2):414-20. [CrossRef] [PubMed] 
5. Committee on Sleep Medicine and Research Board on Health Sciences Policy. Sleep disorders and Sleep Deprivation--An Unmet Public Health Problem. Washington, D.C.: National Academies Press, 2006; 404.

6. Klink M, Quan SF. Prevalence of reported sleep disturbances in a general adult population and their relationship to obstructive airways diseases. Chest. 1987;91(4):540-6. [CrossRef] [PubMed]

7. Williams RL, Karacan I, Hursch CJ. Electroencephalography (EEG) of Human Sleep: Clinical Applications. New York: John Wiley \& Sons, 1974; 169.

8. Redline S, Kirchner HL, Quan SF, Gottlieb DJ, Kapur V, Newman A. The effects of age, sex, ethnicity, and sleep-disordered breathing on sleep architecture. Arch Intern Med. 2004;164(4):406-18. [CrossRef] [PubMed]

9. van den Berg JF, Miedema HM, Tulen JH, Hofman A, Neven AK, Tiemeier H. Sex differences in subjective and actigraphic sleep measures: a population-based study of elderly persons. Sleep. 2009;32(10):1367-75. [PubMed]

10. Bixler EO, Papaliaga MN, Vgontzas AN, et al. Women sleep objectively better than men and the sleep of young women is more resilient to external stressors: effects of age and menopause. J Sleep Res. 2009;18(2):221-8. [CrossRef] [PubMed]

11. Ursin R, Bjorvatn B, Holsten F. Sleep duration, subjective sleep need, and sleep habits of 40- to 45-year-olds in the Hordaland Health Study. Sleep. 2005;28(10):1260-9. [CrossRef]

12. Goel N, Kim H, Lao RP. Gender differences in polysomnographic sleep in young healthy sleepers. Chronobiol Int. 2005;22(5):905-15. [CrossRef] [PubMed]

13. Quan SF, Howard BV, Iber C, et al. The Sleep Heart Health Study: design, rationale, and methods. Sleep. 1997;20(12):1077-85. [PubMed]

14. Lind BK, Goodwin JL, Hill JG, Ali T, Redline S, Quan SF. Recruitment of healthy adults into a study of overnight sleep monitoring in the home: experience of the Sleep Heart Health Study. Sleep Breath. 2003;7(1):13-24. [CrossRef] [PubMed]

15. Shambroom JR, Fabregas SE, Johnstone J. Validation of an automated wireless system to monitor sleep in healthy adults. J Sleep Res. 2012;21(2):221-30. [CrossRef] [PubMed]

16. Griessenberger H, Heib DP, Kunz AB, Hoedlmoser K, Schabus M. Assessment of a wireless headband for automatic sleep scoring. Sleep Breath. 2013;17(2):747-52. [CrossRef] [PubMed]

17. Redline S, Sanders MH, Lind BK, et al. Methods for obtaining and analyzing unattended polysomnography data for a multicenter study. Sleep Heart Health Research Group. Sleep. 1998;21(7):759-67. [PubMed]

18. Singareddy R, Vgontzas AN, Fernandez-Mendoza J, et al. Risk factors for incident chronic insomnia: a general population prospective study. Sleep Med. 2012;13(4):346-53. [CrossRef] [PubMed]

19. Bixler EO, Vgontzas AN, Lin HM, Vela-Bueno A, Kales A. Insomnia in central Pennsylvania. J Psychosom Res. 2002;53(1):589-92. [CrossRef] [PubMed]

20. Spira AP, Kaufmann CN, Kasper JD, et al. Association between insomnia symptoms and functional status in U.S. older adults. J Gerontol B Psychol Sci Soc Sci. 2014;69 Suppl 1:S35-41. [CrossRef] [PubMed] 
21. Walsh JK. Clinical and socioeconomic correlates of insomnia. J Clin Psychiatry . 2004;65 Suppl 813-19. [PubMed]

22. Ohayon MM. Epidemiology of insomnia: what we know and what we still need to learn. Sleep Med Rev. 2002;6(2):97-111. [CrossRef] [PubMed]

23. Walsleben JA, Kapur VK, Newman AB, et al. Sleep and reported daytime sleepiness in normal subjects: the Sleep Heart Health Study. Sleep. 2004;27(2):293-8. [PubMed]

24. Bixler EO, Kales A, Jacoby JA, Soldatos CR, Vela-Bueno A. Nocturnal sleep and wakefulness: effects of age and sex in normal sleepers. Int J Neurosci. 1984;23(1):33-42. [CrossRef] [PubMed]

25. Hoch CC, Dew MA, Reynolds CF,3rd, et al. A longitudinal study of laboratory- and diary-based sleep measures in healthy "old old" and "young old" volunteers. Sleep. 1994;17(6):489-96. [PubMed]

26. Kobayashi R, Kohsaka M, Fukuda N, Honma H, Sakakibara S, Koyama T. Gender differences in the sleep of middle-aged individuals. Psychiatry Clin Neurosci. 1998;52(2):186-7. [CrossRef] [PubMed]

27. Hume KI, Van F, Watson A. A field study of age and gender differences in habitual adult sleep. J Sleep Res. 1998;7(2):85-94. [CrossRefl [PubMed]

28. Toussaint $M$, Luthringer $R$, Schaltenbrand $\mathrm{N}$, et al. Changes in EEG power density during sleep laboratory adaptation. Sleep. 1997;20(12):1201-7. [PubMed]

29. Hirscher V, Unbehaun T, Feige B, Nissen C, Riemann D, Spiegelhalder K. Patients with primary insomnia in the sleep laboratory: do they present with typical nights of sleep? J Sleep Res. 2015; Feb 9. [Epub ahead of print] [CrossRef] [PubMed]

30. Moser D, Kloesch G, Fischmeister FP, Bauer H, Zeitlhofer J. Cyclic alternating pattern and sleep quality in healthy subjects--is there a first-night effect on different approaches of sleep quality? Biol Psychol. 2010;83(1):20-26. [CrossRef] [PubMed]

31. Pollak CP, Tryon WW, Nagaraja H, Dzwonczyk R. How accurately does wrist actigraphy identify the states of sleep and wakefulness? Sleep. 2001;24(8):957-65. [PubMed]

32. Kushida CA, Chang A, Gadkary C, Guilleminault C, Carrillo O, Dement WC. Comparison of actigraphic, polysomnographic, and subjective assessment of sleep parameters in sleep-disordered patients. Sleep Med. 2001;2(5):389-96. [CrossRef] [PubMed]

33. Newell SA, Girgis A, Sanson-Fisher RW, Savolainen NJ. The accuracy of selfreported health behaviors and risk factors relating to cancer and cardiovascular disease in the general population: a critical review. Am J Prev Med. 1999;17(3):21129. [CrossRef] [PubMed]

34. Krueger PM, Friedman EM. Sleep duration in the United States: a cross-sectional population-based study. Am J Epidemiol. 2009;169(9):1052-63. [CrossRef] [PubMed]

35. Leonhard C, Randler C. In sync with the family: children and partners influence the sleep-wake circadian rhythm and social habits of women. Chronobiol Int. 2009;26(3):510-25. [CrossRef] [PubMed] 